\title{
Double stigma in mental health: epilepsy and mental illness
}

\author{
Marco Mula and Kenneth R. Kaufman
}

\section{Background}

Epilepsy and mental illness share similar problems in terms of stigma, as a result of centuries of superstition, ignorance and misbeliefs. Stigma leads not only to discrimination and civil and human rights violations but also to poor access to healthcare and non-adherence or decreased adherence to treatment, ultimately increasing morbidity and mortality. Despite continuous efforts in fighting stigma in these conditions, there is very limited knowledge on the phenomenon of double stigma, meaning the impact of having two stigmatised conditions at the same time.

\section{Aims}

To discuss double stigma in mental health with special reference to epilepsy.

\section{Method}

Articles were identified through searches in PubMed up to 31 October 2019 using the search terms 'epilepsy', 'psychiatric disorders', 'stigma' and additional material was identified from the authors' own files and from chosen bibliographies.

\section{Results}

Double stigma is gaining attention for other stigmatised medical conditions, such as HIV, however, the literature on epilepsy is almost non-existent and this is quite astonishing given that one in three people with epilepsy have a lifetime diagnosis of a psychiatric condition. Felt (perceived) stigma and psychiatric disorders, particularly depression, create a vicious circle in epilepsy maintaining both, as depression correlates with stigma and vice versa as well as epilepsy and depression serving as bidirectional risk factors. This phenomenon has no geographical and economic boundaries as similar data have been reported for low-income and high-income countries.

\section{Conclusions}

Governments and policymakers as well as health services, patients' organisations, families and the general public need to be aware of the phenomenon of double stigma in order to develop campaigns and interventions tailored for these patients.

\section{Keywords}

Epilepsy; stigma; double stigma; depression; psychiatric disorders.

\section{Copyright and usage}

(c) The Author(s), 2020. Published by Cambridge University Press on behalf of The Royal college of Psychiatrists. This is an Open Access article, distributed under the terms of the Creative commons Attribution licence (http://creativecommons.org/ licenses/by/4.0/), which permits unrestricted re-use, distribution, and reproduction in any medium, provided the original work is properly cited.

\section{Background}

Epilepsy is a serious neurological disorder affecting approximately 50 million people worldwide. ${ }^{1,2}$ In high-income countries, incidence rates range between 40 and 70/100 000 persons/year, with higher rates among children and elderly people. ${ }^{3}$ Incidence rates are much higher in resource-poor countries, being above 120/100 000/year, but even in high-income countries, poor people seem to have a higher incidence. ${ }^{4,5}$ According to the World Health Organization (WHO), epilepsy accounts for about $0.5 \%$ of the global burden of all diseases with total annual costs, in Europe in 2004, of approximately 15.5 billion Euros. ${ }^{6}$

People with epilepsy are among the most vulnerable in our society because epilepsy is a hidden disability and remains today a highly stigmatised condition because of ignorance and superstition caused by centuries of misconceptions towards this disorder. ${ }^{7}$ Social stigma is a key aspect of chronic illnesses and negatively affects quality of life. It is characterised by different components, including enacted stigma (external behaviours and discrimination) and felt (perceived) stigma (shame and expectation of discrimination). ${ }^{8,9}$ Stigma leads not only to discrimination and civil and human rights violations but also to poor access to healthcare and decreased adherence to treatment, ultimately increasing morbidity and mortality. Mental illness shares with epilepsy exactly the same issues because of centuries of misbeliefs, ignorance and superstition about mental health problems with similar consequences in terms of discrimination, violation of human rights and poor access to health resources.

\section{Double stigma}

What happens when two highly stigmatised conditions sensitive to cultural themes occur in the same individual? This phenomenon is known as double stigma and it is now getting attention for psychiatric disorders in other stigmatised medical conditions such as, for example, HIV, tuberculosis or obesity. ${ }^{10}$ However, there is still very limited attention to the problem of double stigma in people with mental health issues and epilepsy. In this narrative review, we aimed at discussing the issue of double stigma in mental health with special reference to epilepsy.

\section{Method}

Articles were identified through searches in PubMed up to 31 October 2019 using the search terms 'epilepsy', 'psychiatric disorders', 'stigma'. No language restrictions were applied. This search generated 111 abstracts. Articles were selected based on originality and relevance to the present topic. Additional articles were identified from the authors' own files and from chosen bibliographies.

\section{Results}

\section{How frequent are mental health problems in epilepsy?}

Mental health problems are not uncommon in epilepsy. Data from cross-sectional epidemiological studies show that one in three people with epilepsy have a lifetime history of a psychiatric disorder and all major psychiatric disorders show prevalence rates in people with epilepsy higher than those reported in the general population. ${ }^{11}$ Furthermore, it is now established that there is a bidirectional relationship between epilepsy and psychiatric disorders. ${ }^{12}$

In adults, a meta-analysis of 14 population-based studies showed an overall prevalence of active depression in epilepsy of 
$23.1 \%$ (95\% CI 20.6-28.3\%) with an increased overall risk of 2.77 (95\% CI 2.09-3.67) compared with the general population. ${ }^{13}$ These estimates, however, vary considerably across studies depending on the ascertainment source (i.e. self-report versus screening tools versus structured clinical interviews), countries, regions and settings. A meta-analysis on anxiety disorders in over 3000 people with epilepsy showed a pooled prevalence of $20.2 \%$ (95\% CI 15.3-26.0) with generalised anxiety disorder being most common (10.2\%; 95\% CI 7.7-13.5\%). ${ }^{14} \mathrm{~A}$ meta-analysis of 58 studies of psychosis and related disorders showed a pooled prevalence of 5.6\% (95\% CI 4.8-6.4\%) in unselected samples increasing to $7 \%$ (95\% CI $4.9-9.1 \%)$ in people with temporal lobe epilepsy, with a pooled odds ratio for risk of psychosis compared with the general population of 7.8 (95\% CI 2.8-21.8). ${ }^{15}$ Data from epilepsy surgery samples suggest an even higher prevalence. ${ }^{16}$ Still, studies in selected samples of patients with drug-resistant epilepsy have shown prevalence rates for psychiatric disorders up to $60 \% .{ }^{17}$

Data from children and adolescents with epilepsy are not different despite an obvious emphasis on developmental disorders. A population-based study in 85 children and adolescents (aged 5-15) with active epilepsy in West Sussex in the UK reported a prevalence of attention-deficit hyperactivity disorder (ADHD) of around $33 \%$, autistic spectrum disorder of $21 \%$, depression of $7 \%$ and anxiety of $13 \% .^{18}$ A nationwide Norwegian registry study in an unselected paediatric population of over 1000000 children reported developmental and psychiatric comorbidities in $43 \%$ of children with epilepsy, with overall odds ratios (compared with the general population of children) of 10.7 (95\% CI 9.5-12.1) for autism, 5.4 (95\% CI 4.85.9) for ADHD, 2.3 (95\% CI 1.8-3.0) for anxiety disorders and 1.8 (95\% CI 1.4-2.5) for depression. ${ }^{19}$ A study of 140 adolescents with epilepsy attending a Hong Kong hospital out-patient neurology clinic reported $22.1 \%$ rates for depression and $32.8 \%$ for anxiety. ${ }^{20}$

\section{Stigma and double stigma in mental health}

Stigma is a complex phenomenon and research in this area involves specialised disciplines including social sciences and social psychology. The French sociologist Emile Durkheim was probably the first to explore stigma as a social phenomenon but research on stigma in mental health probably started in the 1960s with the American sociologist Erwin Goffman, ${ }^{21}$ followed by the publications of Thomas Scheff ${ }^{22}$ and Bruce Link ${ }^{23}$. However, at that time, the debate focused on how psychiatry was organised, and how this was responsible for the stigma and public attitude towards people with mental health problems. Subsequent research on stigma in mental health progressed identifying different types of stigma and social group processes. ${ }^{24-26}$ The labelling, stereotyping, separation from others and consequent status loss are the key elements of stigma and they are 'relevant only in a power situation that allows them to unfold'. ${ }^{27,28}$ These studies have highlighted how powerful stereotypes are in our society and their deleterious impact primarily on patients themselves. In fact, negative stereotypes are so ingrained in the collective belief that they become an accepted part of people's belief including patients who internalise how society devalues them. This process is a key element of felt (perceived) stigma and it makes patients feel not empowered to change the situation and, ultimately, maintain the stigma itself.

Negative stereotypes about mental illness are well known. A survey investigating beliefs of random Web users around the world showed that only $7 \%$ of people believe that psychiatric disorders could be overcome and between $8 \%$ (high-income countries) and 16\% (low-income countries) of people believe that individuals with mental health issues are more violent than others. ${ }^{29}$ A cross-sectional survey in people with first-episode psychosis or depression investigated levels of discrimination through face-to-face interview. ${ }^{30}$ People with depression reported greater discrimination in regard to neighbours, dating, education, marriage, religious activities, physical health and acting as a parent than participants with first-episode psychosis. Data from a large prospective population study in Norway showed high chances of divorce in couples where one of the two is diagnosed with a mental illness. ${ }^{31}$ A US study comparing fictitious job applications $(n=635)$ listing mental illness versus physical injury, showed significant discrimination for candidates with a history of mental illness, and this discrimination did not differ for jobs that could be done away from an office setting. ${ }^{32}$

The main consequence of stigma is not simply a negative impact on quality of life for people with mental illness, as stigma has deleterious consequences from a clinical perspective serving as a barrier to health-seeking/diagnosis, treatment and adherence. ${ }^{33}$ A systematic review investigating the relationship between mental healthrelated stigma and help-seeking clearly showed that stigmatising attitudes towards people with a mental illness is associated with less active help-seeking from patients and their relatives. ${ }^{34}$ In this context, people with an already stigmatised condition often do not reveal their mental state to healthcare professionals for fear of being stigmatised further. Also, healthcare professionals dealing with people with epilepsy are often not skilled in detecting psychological symptoms and, even when they do, they often fail to take the necessary action for further assessment, management and referral. ${ }^{35,36}$ For all these reason, people with double stigma have to fight further in order to receive the best possible care (Appendix).

The European Mental Health Action Plan 2013-2020 has specifically included, among the proposed actions, evidence-based anti-stigma activities in high-risk groups. ${ }^{37}$ In 2018, the WHO published the United Nations Common Position on Ending HIV, TB and Viral Hepatitis through Intersectoral Collaboration. ${ }^{38}$ Among the shared principles, it is specifically mentioned that ending these epidemics is not just the absence of the disease but also a state of complete, physical, mental and social well-being, acknowledging the issue of double stigma in these patients. It is quite astonishing that none of these documented listed epilepsy among those medical conditions already stigmatised.

\section{The double stigma of epilepsy and mental health: a complex paradigm}

The impact of stigma is immediately evident on the more intimate life domains of people such as cohabitation and marriage. Patients with epilepsy are less likely to be married or more likely to be divorced as compared with people with other chronic medical conditions. ${ }^{39-41}$ A systematic review of the social outcomes of adults with a history of childhood-onset epilepsy showed that only one in three people were in a romantic relationship, one in three lived independently and one in five had children. ${ }^{42}$ In low-income countries, people with epilepsy are particularly vulnerable to discrimination as in many of these countries there are no anti-discrimination laws or policies in place. A study from Tanzania, showed that only one in three people with epilepsy was in education or in paid employment. ${ }^{43}$ However, stigma easily overcomes anti-discrimination laws and policies and problems are very similar in high-income countries where anti-discrimination laws may not be effective. A survey from Australia showed that $47 \%$ of patients with epilepsy were able to document unfair treatment in the workplace. ${ }^{44} \mathrm{~A}$ systematic review of employability in people with epilepsy showed a mean adjusted employment rate of $58 \%$ with no significant differences between continents. ${ }^{45}$ Still, this study showed similar employment rates in people with uncontrolled and those with controlled seizures, suggesting that unemployment is likely to be related to non-clinical factors. ${ }^{45}$

The concept of double stigma in epilepsy and mental health is more complex than the simple additional effects of the two stigmatised 
conditions. In fact, felt (perceived) stigma is an important determinant per se of mental health problems in epilepsy, creating a vicious circle. ${ }^{46,47}$ In epilepsy, perceived stigma is a risk factor for the development of mood and anxiety disorders, ${ }^{48,49}$ which, at the same time, are risk factors for perceived stigma, along with other personality features. $^{50,51}$ This phenomenon is present in low-income as well as high-income countries, independently of background, although specific cultures may have greater degrees of stigma. A study from Ethiopia showed that perceived stigma is associated with depression in people with epilepsy. ${ }^{52}$ In the same way, a study from Italy showed that feeling stigmatised correlates with depressive symptoms rather than seizure frequency. ${ }^{53}$ A systematic review of clinical correlates of stigma in adults with epilepsy showed that stigma is associated with depression and anxiety. ${ }^{54}$

Stigma affects not only patients but also their caregivers and has negative consequences on their mental health. ${ }^{55,56} \mathrm{~A}$ cross-sectional study from the USA showed that caregivers of people with drug-resistant epilepsy experience high perceived stigma and burden levels. ${ }^{57}$ In low- and middle-income countries, $20 \%$ of mothers of children with epilepsy feel stigmatised because of their child's neurological condition. ${ }^{58}$ The caregiver's perception of burden, together with the level of family functioning, are indirectly correlated with depressive symptoms in people with epilepsy via the mediating effect of caregiver depression. ${ }^{59}$ The same phenomena are reported also in highincome countries. A UK study showed that mothers of young children with epilepsy report high levels of parenting stress as compared with mothers of children with non-epilepsy related neurodisabilities. ${ }^{60}$

Studies addressing the phenomenon of double stigma in epilepsy are almost non-existent. A study from Brazil showed that cohabiting relatives of people with epilepsy and depression experience more stigma than those with epilepsy only. ${ }^{61}$ A study from Bosnia Herzegovina, showed that patients with epilepsy and depression present with higher levels of stigma as compared with those with epilepsy only. ${ }^{62}$ However, the phenomenon of double stigma is not analysed in detail.

What can be done to address the problem? Anti-stigma campaigns and educational initiatives about epilepsy can have positive effects on well-being and mental health problems. An educational campaign in rural Bolivia aimed at improving knowledge towards epilepsy showed that the improved knowledge and attitude towards epilepsy was associated with reduced stigma, better quality of life and fewer depressive symptoms. ${ }^{63}$ However, as pointed out by a study from the Philippines, these strategies may not always be successful in the context of double stigma if context-specific approaches are not considered. ${ }^{64}$ It is not possible to develop effective campaigns and policies on double stigma in epilepsy and mental health without a clear analysis of the problem and for this reason, further studies on this phenomenon are urgently needed.

The new definition of epilepsy published in 2014 now defines epilepsy as a disorder of the brain characterised not just by recurrent seizures but also by its psychosocial consequences ${ }^{65}$ and the new classification of syndromes published in 2017 recognises comorbidities as an important part of the diagnostic process. ${ }^{66}$ Furthermore, the new WHO global report on epilepsy also mentions the presence of psychiatric disorders in epilepsy and the importance of addressing them. ${ }^{1}$ These necessary preliminary steps are helpful as they lead to the global acknowledgement of mental health problems in people with epilepsy as well as the associated double stigma but significant work still needs to be done in terms of education (for example society, patients, and healthcare providers) and access to care.

\section{Discussion}

Lack of studies on the phenomenon of double stigma represents a major concern and more research in this area is needed. Both quantitative and qualitative studies as well as systematic reviews and meta-analyses are required to better appreciate the key issues that exist for patients with both epilepsy and mental disorders. In fact, future anti-stigma campaigns will need to take into account the phenomenon of double stigma in order to develop targeted and focused interventions.

Stigma is unacceptable and everyone has the right to be protected from it. Counteracting stigma and discrimination is a duty of governments, health services, medical schools, medical societies, patients' organisations, families and the general public. Advocacy can take many forms and it represents the best way to fight stigma and to empower people with epilepsy and mental health problems. ${ }^{67}$

Marco Mula (D), Institute of Medical and Biomedical Education, St George's University of London, UK; and the Atkinson Morley Regional Neuroscience Centre, St George's University Hospitals NHS Foundation Trust, UK; Kenneth R. Kaufman (D), Robert Wood Johnson Medical School, Rutgers University, New Brunswick, USA; and Institute of Psychiatry, Psychology, and Neuroscience, King's College London, UK

Correspondence: Marco Mula. Email: mmula@sgul.ac.uk

First received 26 Feb 2020, final revision 30 May 2020, accepted 4 Jun 2020

\section{Author contributions}

M.M. conceptualised the paper and wrote the first draft. K.R.K. conceptualised the paper, reviewed for intellectual content, and added critical comments. All authors approved the original submission. All authors helped to revise and approved the final version.

\section{Declaration of interest}

K.R.K. is the Editor-in-Chief of BJPSych Open and a member of the BJPSych editorial board. ICMJE forms are in the supplementary material, available online at https://doi.org/10.1192/ bjo.2020.58.

\section{Appendix}

Consequences of double stigma in people with epilepsy and mental illness

\section{Factor}

Public attitude, knowledge and misbeliefs about epilepsy and mental illness

Patients' reluctance to disclose mental health problems when affected by a stigmatised condition such as epilepsy Felt (perceived) stigma leading to increased rates of mood and anxiety disorders creating a vicious circle

Lack of training of neurologists and Failure to identify, prevent and treat psychiatrists in identifying and treating psychiatric disorders in epilepsy

Lack of integrated campaigns addressing double stigma psychiatric disorders in epilepsy

Lack of integrated campaigns addressing double stigma

Failure to identify needs of people with double stigma

Limited knowledge on the double stigma phenomenon

\section{References}

1 World Health Organization. Epilepsy: A Public Health Imperative. WHO, 2019 (http://www.who.int/mental_health/neurology/epilepsy/report_2019/en/).

2 de Boer HM, Mula M, Sander JW. The global burden and stigma of epilepsy. Epilepsy Behav 2008; 12: 540-6.

3 MacDonald BK, Cockerell OC, Sander JW, Shorvon SD. The incidence and lifetime prevalence of neurological disorders in a prospective community-based study in the UK. Brain 2000; 123: 665-76. 
4 Ngugi AK, Bottomley C, Kleinschmidt I, Wagner RG, Kakooza-Mwesige A Ae-Ngibise $\mathrm{K}$, et al. Prevalence of active convulsive epilepsy in sub-Saharan Africa and associated risk factors: cross-sectional and case-control studies. Lancet Neurol 2013; 12: 253-63.

5 Ngugi AK, Kariuki SM, Bottomley C, Kleinschmidt I, Sander JW, Newton CR. Incidence of epilepsy: a systematic review and meta-analysis. Neurology 2011; 77: 1005-12.

6 Pugliatti M, Beghi E, Forsgren L, Ekman M, Sobocki P. Estimating the cost of epilepsy in Europe: a review with economic modeling. Epilepsia 2007; 48: 2224-33.

7 Temkin O. The Falling Sickness: A History of Epilepsy from the Greeks to the Beginnings of Modern Neurology. JHU Press, 1994.

8 Scambler G, Hopkins A. Being epileptic: coming to terms with stigma. Sociol Health IIIn 1986; 8: 26-43.

9 Kaufman KR. Epilepsy and secondary perceived stigma in a social setting: a night at the theater. Epilepsy Behav 2016; 61: 138-40.

10 Daftary A. HIV and tuberculosis: the construction and management of double stigma. Soc Sci Med 2012; 74: 1512-9.

11 Salpekar JA, Mula M. Common psychiatric comorbidities in epilepsy: how big of a problem is it? Epilepsy Behav 2019; 98: 293-7.

12 Hesdorffer DC, Ishihara L, Mynepalli L, Webb DJ, Weil J, Hauser WA. Epilepsy, suicidality, and psychiatric disorders: a bidirectional association. Ann Neurol 2012; 72: 184-91.

13 Fiest KM, Dykeman J, Patten SB, Wiebe S, Kaplan GG, Maxwell CJ, et al. Depression in epilepsy: a systematic review and meta-analysis. Neurology 2013; 80: 590-9.

14 Scott AJ, Sharpe L, Hunt C, Gandy M. Anxiety and depressive disorders in people with epilepsy: a meta-analysis. Epilepsia 2017; 58: 973-82.

15 Clancy MJ, Clarke MC, Connor DJ, Cannon M, Cotter DR. The prevalence of psychosis in epilepsy; a systematic review and meta-analysis. BMC Psychiatry 2014; 14: 75.

16 Buranee K, Teeradej S, Chusak L, Michael M. Epilepsy-related psychoses and psychotic symptoms are significantly reduced by resective epilepsy surgery and are not associated with surgery outcome or epilepsy characteristics: a cohort study. Psychiatry Res 2016; 245: 333-9.

17 Hellwig S, Mamalis P, Feige B, Schulze-Bonhage A, van Elst LT. Psychiatric comorbidity in patients with pharmacoresistant focal epilepsy and psychiatric outcome after epilepsy surgery. Epilepsy Behav 2012; 23: 272-9.

18 Reilly C, Atkinson P, Das KB, Chin RFMC, Aylett SE, Burch V, et al. Neurobehavioral comorbidities in children with active epilepsy: a populationbased study. Pediatrics 2014; 133: e1586-93.

19 Aaberg KM, Bakken IJ, Lossius MI, Lund Søraas C, Håberg SE, Stoltenberg C, et al. Comorbidity and childhood epilepsy: a nationwide registry study. Pediatrics 2016; 138; e20160921.

20 Kwong KL, Lam D, Tsui S, Ngan M, Tsang B, Lai TS, et al. Anxiety and depression in adolescents with epilepsy. J Child Neurol 2016; 31: 203-10.

21 Goffman E. Stigma: Notes on the Management of Spoiled Identity (New Ed edn) Penguin, 1990.

22 Scheff TJ. Being Mentally III: A Sociological Theory. Aldine, 1966.

23 Link BG. Stigma: many mechanisms require multifaceted responses. Epidemiol Psichiatr SOC 2001; 10: 8-11.

24 Link BG, Yang LH, Phelan JC, Collins PY. Measuring mental illness stigma. Schizophr Bull 2004; 30: 511-41.

25 Corrigan P. How stigma interferes with mental health care. Am Psychol 2004; 59: $614-25$.

26 Corrigan PW, Kleinlein P. The impact of mental illness stigma. In On the Stigma of Mental IIIness: Practical Strategies for Research and Social Change (ed PW Corrigan). American Psychological Association, 2005.

27 Link BG, Phelan JC. Conceptualizing Stigma. Annu Rev Sociol 2001; 27 363-85.

28 de Boer HM. Epilepsy stigma: moving from a global problem to global solutions. Seizure 2010; 19: 630-6

29 Seeman N, Tang S, Brown AD, Ing A. World survey of mental illness stigma. J Affect Disord 2016; 190: 115-21.

30 Corker EA, Beldie A, Brain C, Jakovljevic M, Jarema M, Karamustafalioglu O, et al. Experience of stigma and discrimination reported by people experiencing the first episode of schizophrenia and those with a first episode of depression: the FEDORA project. Int J SOc Psychiatry 2015; 61: 438-45.

31 Idstad M, Torvik FA, Borren I, Rognmo K, Røysamb E, Tambs K. Mental distress predicts divorce over 16 years: the HUNT study. BMC Public Health 2015; 15: 320.

32 Hipes C, Lucas J, Phelan JC, White RC. The stigma of mental illness in the labor market. Soc Sci Res 2016; 56: 16-25.
33 Sirey JA, Bruce ML, Alexopoulos GS, Perlick DA, Friedman SJ, Meyers BS. Stigma as a barrier to recovery: perceived stigma and patient-rated severity of illness as predictors of antidepressant drug adherence. Psychiatr Serv 2001; 52: $1615-20$

34 Schnyder N, Panczak R, Groth N, Schultze-Lutter F. Association between mental health-related stigma and active help-seeking: systematic review and meta-analysis. Br J Psychiatry 2017; 210: 261-8.

35 Hesdorffer DC. Comorbidity between neurological illness and psychiatric disorders. CNS Spectr 2016; 21: 230-8.

36 Lopez MR, Schachter SC, Kanner AM. Psychiatric comorbidities go unrecognized in patients with epilepsy: 'You see what you know'. Epilepsy Behav 2019; 98: 302-5.

37 World Health Organization, Regional Office for Europe. The European Mental Health Action Plan 2013-2020. WHO, 2015 (http://www.euro.who.int/_data/ assets/pdf_file/0020/280604/WHO-Europe-Mental-Health-Acion-Plan-2013-2020. pdf?ua=1).

38 World Health Organization, Regional Office for Europe. United Nations Common Position on Ending HIV TB and Viral Hepatitis through Intersectoral Collaboration. WHO Regional Office for Europe, 2018.

39 Friedrich L, Taslak M, Tomasović S, Bielen I. How does the label 'epileptic' influence attitudes toward epilepsy? Seizure 2015; 33: 54-9.

40 Riasi H, Rajabpour Sanati A, Ghaemi K. The stigma of epilepsy and its effects on marital status. SpringerPlus 2014; 3: 762.

41 Tedrus GMAS, Fonseca LC, Pereira RB. Marital status of patients with epilepsy: factors and quality of life. Seizure 2015; 27 : 66-70.

42 Puka K, Tavares TP, Speechley KN. Social outcomes for adults with a history of childhood-onset epilepsy: A systematic review and meta-analysis. Epilepsy Behav 2019; 92: 297-305.

43 Goodall J, Salem S, Walker RW, Gray WK, Burton K, Hunter E, et al. Stigma and functional disability in relation to marriage and employment in young people with epilepsy in rural Tanzania. Seizure 2018: 54: 27-32.

44 Bellon M, Walker C, Peterson C, Cookson P. The 'E' word: epilepsy and perceptions of unfair treatment from the 2010 Australian Epilepsy Longitudinal Survey. Epilepsy Behav 2013; 27: 251-6.

45 Wo MCM, Lim KS, Choo WY, Tan CT. Employability in people with epilepsy: a systematic review. Epilepsy Res 2015; 116: 67-78.

46 Yeni K, Tulek Z, Simsek OF, Bebek N. Relationships between knowledge, attitudes, stigma, anxiety and depression, and quality of life in epilepsy: a structural equation modeling. Epilepsy Behav 2018; 85: 212-7.

47 Yıldırım Z, Ertem DH, Ceyhan Dirican A, Baybaş S. Stigma accounts for depression in patients with epilepsy. Epilepsy Behav 2018; 78: 1-6.

48 Peterson CL, Walker C, Shears G. The social context of anxiety and depression: exploring the role of anxiety and depression in the lives of Australian adults with epilepsy. Epilepsy Behav 2014; 34: 29-33.

49 Lee S-A, Jeon JY, No S-K, Park H, Kim O-J, Kwon J-H, et al. Factors contributing to anxiety and depressive symptoms in adults with new-onset epilepsy. Epilepsy Behav 2018; 88: 325-31.

50 Shi $Y$, Wang S, Ying J, Zhang M, Liu P, Zhang $\mathrm{H}$, et al. Correlates of perceived stigma for people living with epilepsy: a meta-analysis. Epilepsy Behav 2017; 70: $198-203$

51 Lee G-H, Lee S-A, No S-K, Lee S-M, Ryu J-Y, Jo K-D, et al. Factors contributing to the development of perceived stigma in people with newly diagnosed epilepsy: a one-year longitudinal study. Epilepsy Behav 2016; 54: 1-6.

52 Chaka A, Awoke T, Yohannis Z, Ayano G, Tareke M, Abate A, et al. Determinants of depression among people with epilepsy in Central Ethiopia. Ann Gen Psychiatry 2018; 17: 27

53 Tombini M, Assenza G, Quintiliani L, Ricci L, Lanzone J, De Mojà R, et al. Epilepsy-associated stigma from the perspective of people with epilepsy and the community in Italy. Epilepsy Behav 2019; 98: 66-72.

54 Baker D, Eccles FJR, Caswell HL. Correlates of stigma in adults with epilepsy: a systematic review of quantitative studies. Epilepsy Behav 2018; 83: 67-80.

55 Seid S, Demilew D, Yimer S, Mihretu A. Prevalence and associated factors of mental distress among caregivers of patients with epilepsy in ethiopia: a cross-sectional study design. Psychiatry J 2018; 2018: 2819643.

56 Rani A, Thomas PT. Stress and perceived stigma among parents of children with epilepsy. Neurol Sci 2019; 40: 1363-70.

57 Hansen B, Szaflarski M, Bebin EM, Szaflarski JP. Affiliate stigma and caregiver burden in intractable epilepsy. Epilepsy Behav 2018; 85: 1-6.

58 Elafros MA, Sakubita-Simasiku C, Atadzhanov M, Haworth A, Chomba E, Birbeck GL. Stigma and psychiatric morbidity among mothers of children with epilepsy in Zambia. Int Health 2013; 5: 288-94.

59 Han S-H, Kim B, Lee S-A. Korean QoL in Epilepsy Study Group. Contribution of the family environment to depression in Korean adults with epilepsy. Seizure 2015; 25: 26-31. 
60 Reilly C, Atkinson P, Memon A, Jones C, Dabydeen L, Das KB, et al. Parenting stress and perceived stigma in mothers of young children with epilepsy: a case-control study. Epilepsy Behav 2018; 89: 112-7.

61 Tedrus GMAS, Pereira RB, Zoppi M. Epilepsy, stigma, and family. Epilepsy Behav 2018; 78: 265-8

62 Suljic $E$, Hrelja $A$, Mehmedika $T$. Whether the presence of depressions increases stigmatization of people with epilepsy? Mater Socio-Medica 2018; 30: 265-9.

63 Giuliano L, Cicero CE, Padilla S, Rojo Mayaregua D, Camargo Villarreal WM Sofia $\mathrm{V}$, et al. Knowledge, stigma, and quality of life in epilepsy: results before and after a community-based epilepsy awareness program in rural Bolivia. Epilepsy Behav 2019; 92: 90-7.

64 Tanaka C, Tuliao MTR, Tanaka E, Yamashita T, Matsuo H. A qualitative study on the stigma experienced by people with mental health problems and epilepsy in the Philippines. BMC Psychiatry 2018; 18: 325
65 Fisher RS, Acevedo C, Arzimanoglou A, Bogacz A, Cross JH, Elger CE, et al. ILAE official report: a practical clinical definition of epilepsy. Epilepsia 2014; 55: 475-82.

66 Scheffer IE, Berkovic S, Capovilla G, Connolly MB, French J, Guilhoto L, et al. ILAE classification of the epilepsies: Position paper of the ILAE Commission for Classification and Terminology. Epilepsia 2017; 58: 512-21.

67 Sudlesky L, Schachter S. eds. Visions: The Inspirational Journeys of Epilepsy Advocates. Oxford University Press, 2020. 